larger scale with oil of turpentine, and he detected the existence of currents, which are in accord with the view that the unelectrified liquid flows up the exterior of the cylinder, becomes electrified by contact, and is repelled down its axis. In view of this explanation, and the movements assumed can be clearly seen in the phenyl thiocarbamide, the performance of the experiment on a small scale is not without interest. The possibility of the formation of such violent up-and-down currents in so small a space must depend upon a very nice adjustment between the properties of the liquid and the forces in play. It is obvious that such movements of the liquid must be a disturbing element in any attempt to make the lines of electric force visible.

Again, if a solid powder be suspended in a liquid into which electrified solids are introduced, it tends to accumulate round one of the poles. This subject has been investigated by W. Holtz. Sometimes the powder appears to move in a direction opposed to that in which the liquid is streaming. Sometimes two powders will travel towards different poles.

If powdered antimony sulphide be placed in ether, it settles at the bottom of the liquid, and if either two wires insulated with glass up to their points, or two vertical plates be used as electrodes, on exciting them slightly the solid particles arrange themselves along the lines of force. If the electrification be increased, they cluster round the positive pole. On suddenly reversing the electrification by means of a commutator, they stream along lines of force to the pole from which they were previously repelled. Other methods of obtaining the lines of force have been devised. They can, for instance, be shown by crystals of sulphate of quinine immersed in turpentine.

The tendency of the lines of force to separate one from the other was illustrated by Quincke's experiment. A bubble of air is formed in bisulphide of carbon between two horizontal plates. It is in connection with a small manometer, and when the plates are oppositely excited, the electrical pressure acting at right angles to the lines of force, being greater in the liquid than in air, compels the bubble to contract.

Kerr's experiments depend upon the fact that, since the electrical stress is a tension along the lines of force, and a pressure at right angles to them, a substance in which such a stress is produced assumes a semicrystalline condition in the sense that its properties along, and perpendicular to, the lines of force are different. Light is therefore transmitted with different velocities according as the direction of vibrations coincides with, or is perpendicular to, these lines; and the familar phenomena of the passage of polarized light through crystals may be imitated by an electrically stressed liquid.

The bisulphide of carbon used must be dry, and, to make the phenomena clearly visible, it is necessary that the light should travel through a considerable thickness. Thus, to represent the stress between two spheres, elongated parallel cylinders should be used, the axes of which are parallel to the course of the rays of light. These appear on the screen as two dark circles. Between crossed Nicols, the planes of polarization of which are inclined at $45^{\circ}$ to the horizontal, the field is dark until the cylinders are electrified, when light is restored in the space between them.

If parallel plates with carefully rounded edges, and about 2 millimetres apart, are used, the colours of Newton's rings appear in turn, the red of the third order being sometimes reached. If one plate is convex towards the other, the colours of the higher orders appear in the middle, and travel outwards as the stress is increased. The experiments may be varied by using two concentric cylinders, or two sheets of metal bent twice at right angles to represent a section through a Leyden jar. In the first case a black cross is formed; and in the second, black brushes unite the lower angles of the images of the edges of the plates. By the interposition of a piece of selenite, which shows the blue of the second order, two of the quadrants contained between the arms of the cross become green, and the others red. In like manner the horizontal and vertical spaces between the inner and outer coatings of the "jar" become differently coloured.

There are several phenomena connected with the stress in insulators which present considerable difficulties. Thus in a solid it is found impossible to restore the light between crossed Nicols by a uniform electrical field. That the non-uniformity of the field has nothing to do with the phenomenon in liquids, though at first disputed, is now generally admitted. It may be readily proved by means of a Franklin's pane, of which half is pierced into windows. The glow is much weakened by thus removing part of the uniform field, though it is thus made much less uniform.

Again, though most dielectrics when placed in an electric field expand, the fatty oils contract. Prof. J. J. Thomson has recently pointed out that this indicates that another set of strains are superposed upon those assumed in the ordinary explanations of these phenomena, and by which they may be neutralized or overcome.

In experiments with carbon bisulphide it is necessary to take every precaution against fire. For this purpose the cell which contains the liquid should be immersed in a larger cell, so that if--as sometimes happens-the passage of a spark cracks the glass the liquid may flow into a confined space. This should stand in a tray with turned-up edges, and an extinguisher of tin plate should be at hand to place over the whole apparatus. No Leyden jars should be included in the electrical circuit. The difficulties which formerly arose in the exhibition of experiments in statical electricity owing to the presence of moisture in the air of a lecture-room are now immensely reduced by the Wimshurst machine, which works with unfailing certainty under adverse conditions. A new and very beautiful machine was kindly lent by Mr. Wimshurst for the purposes of the lecture.

\section{NEW BUILDINGS AT CAMBRIDGE FOR PHYSIOLOGY AND ANATOMY.}

$\mathrm{THE}$ energy and success of the Cambridge teachers of science are once more demonstrated by the proposal to build new laboratories, with a large lecture-room, for anatomy and physiology, and a museum and dissectingroom for human anatomy, on a scale commensurate with the importance of the medical and biological school. The present physiological laboratories, which ten years ago were a great advance upon the mere make-shift arrangements that had previously done duty, are now disagreeably overcrowded. At present, Prof. Foster's elementary class is attended by between 190 and 200 students; and the several advanced classes have from twenty to thirty-five students. In the laboratory there are now only places for ninety students of histology; but accommodation has been provided for about seventy more in a temporary building attached to the museum. Inasmuch as the students of the elementary class must all go through the histological course, lasting throughout three terms, it is evident that they can be accommodated only by relays, and that in order to accommodate the advanced students, who have no proper places of their own, much crowding must take place, whereas the advanced students' work-places ought not to be disturbed, as these students need opportunities for continuous work. For chemical physiology there are only eight places available, and there is one fairly large room for physical physiology; there is no adequate lecture-room.

The proposed buildings have once been deferred, plans having been prepared in I884; but it is hoped that the 
delay may have led to the presentation of a better and more complete plan. The details of the scheme would be too long for us to give ; but the result will be to provide an excellent new building extending for 190 feet along Corn Exchange Street, in continuation of the east front of the present buildings for physiology and comparative anatomy, and occupying the whole distance between them and the Corn Exchange. Besides rooms for teachers and demonstrators, aquaria, and preparation-rooms, there will be a new class-room in which I40 additional students for histology can be accommodated. There will be a demonstration-room in which about fifty students at a time can be shown experiments which now have to be omitted owing to the want of such a room. By rearrangement of rooms additional accommodation will be given to chemical physiology and to research, while rooms will be available for advanced students to work without interruption from the elementary classes.

The new lecture-room will be in the middle block, between the anatomical and physiological buildings; internally it is to measure 40 by 45 feet, by 25 feet high to the wall-plate, above which will be an open queen-post trussed roof, with sky-lights in the sides. There will also be a large window in the east gable. This lecture-room will accommodate 240 students, for more than which number it is not yet considered necessary to provicle; although if the school continues to expand till it reaches the dimensions of the Edinburgh School, which is not impossible, a still larger lecture-room will ultimately be required. But the present proposal will give a room far superior to the room now in use, both for anatomy and physiology.

The northern block, for human anatomy, has about 70 feet of frontage, and contains, in addition to offices, Professor's and articulating-rooms, \&x., a museum 40 feet by 60 , lighted by windows in three walls, and 17 feet high, admitting of the construction of a gallery. Above the museum is a dissecting-room of rather larger area, well lighted.

The estimated cost is, for physiology, $£ 4755$; lectureroom, $£ 3338$; human anatomy, £5872: total, £I 3,965 . The report and plans are to be discussed on Saturday next, and we hope they will be promptly carried out, as the anatomical buildings at present in use are painfully inadequate, and physiology is also urgently in need of better accommodation.

\section{NOTES.}

THE subject of the Cruonian Lecture to be delivered before the Royal Society during the present year will be " Preventive Inoculation." The lecture will be delivered by M. Roux, and will be founded on observations made in the Pasteur Institute. It is hoped that M. Pasteur will he present at the lecture.

Mr. EADWARd MUybridge, of Philadelphia, who by arrangement with the Managers of the Royal Institution had agreed to give a discourse after Easter on "The Science of Animal Locomotion in its Relation to Design in Art" (illustrated by the zoopraxiscope), a subject of great novelty and interest, has kindly consented to deliver it on Friday evening, the 22nd instant, Dr. Edgar Crookshank being compelled, through illness, to defer his discourse on "Microbes," which was to have been delivered on that evening.

To meet the expressed wish of the members, the Council of the Mineralogical Society has resolved that two additional general meetings shall be held in London during the current year; the first has been fixed for Tuesday, March 12, and the other for Tuesday, June 25. The general meetings still to be held in London during the year will thus be on the following Tuesdays: March 12, May 7, June 25, November 5 (anniversary). The meetings will be held on the premises of the Geological Society, Burlington House, Piccadilly, at 8 p. m..
ON Monday, March II, Mr. William Jago will begin, at the City and Guilds of London Institute, a course of ten lectures on "Bread-making." The lectures will be delivered on Monday and Thursday evenings at $7 \cdot 30$. The special object of the course is to give, in the simplest possible manner, instruction to practical working bakers as to the nature of the changes which occur during the manufacture of bread.

IN spite of the enthusiasm evoked in Norway by the success of the Nansen Expedition, the national subscription opened to defray the cost has been but poorly responded to. In consequence, Herr Gamél, of Copenhagen, whose munificence enabled the Expedition to start at all, has offered to contribute the balance wanting.

WE regret to have to record the death of the Rev. John George Wood, author of "Common Objects of the Sea-shore" and many other popular works on natural history. He died on Sunday, while on a visit to Coventry, from an attack of peritonitis. Mr. Wood was in his sixty-second year.

THE death is announced of Dr. Johannes Brock, lately Professor of Zoology at Dorpat University. He was well known by his scientific journey to the Indian Archipelago, undertaken with the pecuniary help of the Berlin Academy. He died at Göttingen, where he had been appointed Professor of Natural Science.

DR. J. SOYKA, Professor at the German University at Prague, and formerly at the University of Munich, shot himself during a fit of melancholia, on February 23. He was the author of works on Bacteria.

LAST week, in answer to a question put by Mr. Mundella, with regard to the aid to be granted by the Government to provincial Colleges, the Chancellor of the Exchequer made the following statement :- "A vote for provincial Colleges has been put down in the Estimates for 1889-90. The Government have found considerable difficulty in deciding what Colleges should be entitled to share in it, and in what proportions and on what conditions it should be distributed between them. They have accordingly appointed a small Committee to make particular inquiries and advise them on these points. The Committee will sit at an early date, and its deliberations are not likely to be prolonged. Upon receiving its report the Government will settle the scheme of distribution. The sum voted will, of course, be available for the Colleges which are entitled to share in it during the coming financial year."

THE Owens College is one of the Manchester institutions which benefit by the will of the late Mr. John Rylands. He has bequeathed to it $£ 10,000$.

SOME time ago the Coast Fishing Section of the German Fisheries Society established a zoological station at Ditzum, on the Dollart, where researches on the fauna of the German Ocean were carried on during the summer months. The Society are now making arrangements to keep the station open during the whole year.

A Biological Station, chiefly for the promotion of the fisheries, is to be established in Denmark, at a cost of $£ 2000$, with a yearly subsidy of $£ 480$.

THE Fisheries Exhibition which has just been opened in St. Petersburg is the first Exhibition of this kind that has been held there. It will remain open till the end of April.

ON February 20, about Io p.m., a remarkably brilliant meteor was seen in and around Stavanger, on the west coast of Norway. It radiated in the south-east, and, going in a westerly direction, burst about $35^{\circ}$ above the horizon, without any detonation, but leaving a long trail behind. Its light was a dazzling white. 